\title{
What Do Students with Disabilities Tell Us About the Importance of Family Involvement in the Transition from School to Adult Life?
}

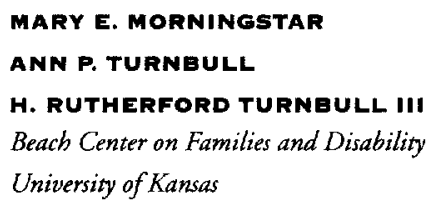

ABSTRACT: This qualitative study used focus groups to explore student perspectives on family involvement in the transition from school to adult life. Four focus groups, including students with learning disabilities, emotional and behavioral disorders, and mild mental retardation, identified pertinent issues concerning how families influence the development of a personal vision for the future, how students with disabilities perceive family involvement in transition planning, and how families influence the development of student self-determination. Results showed the importance to students of family input and support. Implications for transition planning, family roles for support during adulthood, and family-student-school partnership models are discussed.

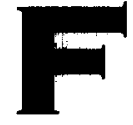
amilies have a critical impact on the successful transition from school to adult life for young adults with disabilities (Everson \& Moon, 1987). In fact, parent participation is considered to be one of the most important elements of transition programs (Sales, Metzler, Everson, \& Moon, 1991; Schultz, 1986) that lead to positive outcomes for young adults with disabilities (Gardner, Chapman, Donaldson,
\& Jacobson, 1988). McNair and Rusch (1991) reported that, in the absence of special funding or special programs, parental involvement is the primary determinant of success in transition programs. In practice, however, parents and professionals experience difficulty in achieving collaborative working relationships (Goldberg \& Kuriloff, 1991; Thornin \& Irvin, 1992; Todis \& Singer, 1991; Turnbull \& Turnbull, 1990). 
Although opportunities for parental involvement in planning educational programs has been mandated since 1975 (Public Law 94-142), the active involvement of students with disabilities is a relatively new concept. Research has shown that student involvement in educational planning is for the most part either nonexistent or passive (Van Reusen \& Bos, 1990). Students who do not have the opportunities to learn to plan and manage their lives will leave school without the skills necessary to achieve positive adult outcomes (Martin, Marshall, \& Maxson, 1993). In fact, Wehmeyer (1992a) concluded that one of the reasons for poor postschool outcomes is that students with disabilities leave school without self-determination.

Several recent models of student involvement in transition planning include creating a self-directed individualized education program (IEP) (Martin et al., 1993); student mastery of self-management skills (Mithaug, Martin, \& Agran, 1987); and assisting students in learning self-advocacy skills (Van Reusen \& Bos, 1994). Though many of these new processes include the involvement of families, the primary focus is on skill development for students.

This article presents the analysis from four focus groups regarding the perspectives held by students with disabilities about the importance of family involvement in transition planning. The information provided by the students is a data subset from a larger study that is seeking to develop a better understanding of the methods and levels of collaboration among all participants in the transition planning process. The data presented in this article, however, focus specifically on students with disabilities and their perspectives regarding (a) family influence on the creation of a vision for their future, (b) family involvement in the transition planning process, and (c) family impact on the student's self-determination.

\section{METHOD}

\section{Qualitative Methodology}

A qualitative method of inquiry was used for this study. Qualitative methods are especially useful for exploratory research where little is known about the phenomenon of interest (Stewart $\&$ Shamdasani, 1990). We used focus groups as the primary source for data collection. A focus group has been defined as a "carefully planned discussion designed to obrain perceptions on a defined area of interest in a permissive and nonthreatening environment" (Krueger, 1988, p. 18). What differentiates focus groups from other forms of qualitative data collection is the presence of group interaction in response to researchers' questions (Morgan \& Krueger, 1993).

\section{Sample}

Using purposive sampling, we selected the focusgroup participants. In contrast to the randomsampling methods in quantitative research, purposive sampling involves the selection of a small number of groups representative of the diverse characteristics of the study population (Lincoln \& Guba, 1985). For this study, we organized groups to represent the viewpoints of students with disabilities in Kansas who should be involved with transition planning. The four focus groups were organized to allow for predominantly homogeneous groups with regard to the similarity of their backgrounds and geographic location. However, groups were mixed by the characteristics of age, knowledge base, experience with transition planning, and with respect to ethnic diversity. These procedures attempt to address the recommendations that groups be homogeneous, but with sufficient variation among participants to allow for contrasting opinions (Krueger, 1988; Stewart \& Shamdasani, 1990). Table 1 provides an overview of sample characteristics of the students.

We recruited participants through personal contact or phone calls. When the researchers did not have direct access to possible focus-group members, groups were organized through contact with administrators and teachers. Students with disabilities who participated in the focus groups were identified as having learning disabilities, emotional and behavioral disorders, and mild mental retardation.

\section{Procedures}

The focus groups lasted approximately $2 \mathrm{hr}$. To make participants feel more comfortable, the research team provided either a pizza lunch prior to 
TABLE 1

Demographic Information of Focus Group Participants

\begin{tabular}{|c|c|c|c|c|c|}
\hline Focus Group & $\begin{array}{l}\text { Geographic } \\
\text { Location }\end{array}$ & $\begin{array}{l}\text { No. in Focus } \\
\text { Group }\end{array}$ & $\begin{array}{c}\text { Disability } \\
\text { Category and No. }\end{array}$ & $\begin{array}{c}\text { Racial } \\
\text { Breakdown and No. }\end{array}$ & $\begin{array}{c}\text { Age of } \\
\text { Participants (Years) }\end{array}$ \\
\hline Group 1 & Rural & 8 & LD - 8 & $\begin{array}{l}\text { Caucasian - } 7 \\
\text { Hispanic - } 1\end{array}$ & $17-19$ \\
\hline Group 2 & Rural & 15 & $\begin{array}{l}\mathrm{LD}-6 \\
\mathrm{BD}-2 \\
\mathrm{MMR}-7\end{array}$ & Caucasian - 15 & $13-19$ \\
\hline Group 3 & Suburban & 11 & $\begin{array}{l}\text { LD - } 4 \\
\text { BD - } 5 \\
\text { MMR - } 2\end{array}$ & $\begin{array}{l}\text { Caucasian - } 8 \\
\text { Hispanic - } 3\end{array}$ & $15-17$ \\
\hline Group 4 & Suburban & 6 & $\mathrm{BD}-6$ & $\begin{array}{l}\text { Caucasian - } 5 \\
\text { African American - } 1\end{array}$ & $13-16$ \\
\hline
\end{tabular}
Note: Abbreviations for disability categories are: LD, learning disabiliries; BD, behavior disorders; MMR, mild mental retarda-
tion.

holding the focus groups, or McDonald's gift certificates after the focus group. In an attempt to create a more familiar and informal environment within which the students could talk freely, the focus groups included time for participants to talk about subjects important to them even if not directly relevant to the focus group questions, attempted to instill humor and good-natured bantering among participants and the moderator, and included frequent breaks and opportunities for the students to move abour.

Focus Group Questions. The content questions for this research study were organized around the three broad research questions:

1. How have families impacted the development of a personal vision for the future?

2. How do students with disabilities perceive their family's involvement with the transition planning process?

3. How have families influenced the students' self-determination?

We generated the specific content of the questions from the review of the literature and previous research regarding student and family involvement in transition planning.

Once we had compiled an initial set of questions and developed a moderator's guide for facilitating the focus groups, we field-tested the focus group format with two groups of students with disabilities (the data from the field tests were not used in the final data analysis). In this way, we modified the questions and pacing of the focus group to elicit more appropriate and relevant responses.

Conducting the Focus Groups. A two-person research team conducted the focus group interviews. The team included a moderator who asked open-ended questions, probed for additional comments, and monitored group discussion; and an observer, who operated the audiocassette recorder, kept track of time, and took accompanying field notes.

The moderator's primary task was to facilitate or guide the focus group in order to collect rich and valid insights about student perceptions regarding family involvement in transition planning. The moderator for this research study was trained in techniques that are considered by researchers to be effective strategies (Lincoln \& Guba, 1985; Morgan \& Krueger, 1993) and have been used in past focus group research (Morningstar, Sarkesian, \& Tisdale, 1993). 


\section{Data Collection}

We used two primary methods to collect the focus group data. All focus groups were audiotaped. These tapes were then fully transcribed for later data analysis. In addition, the observer was responsible for keeping field notes during the discussion. These notes included the main themes that emerged during the focus group and the general atmosphere and emotional responses of the participants. Immediately after the focus group had ended, the moderator and observer met to summarize and compare notes.

\section{Data Analysis}

A qualitative summary of participant comments was the primary method of data analysis for this study (Morgan, 1988). This summary involved reviewing all field notes, summarized notes, and transcripts from each focus group. The moderator and a second researcher analyzed the data, using established ethnographic and content data analysis techniques (Johnson \& LaMontagne, 1993; Kerwin, Ponterotto, Jackson, \& Harris, 1993; Krueger, 1988; Stewart \& Shamdasani, 1990). This procedure involved "cycling through" the transcripts and notes and marking all relevant passages related to each of the questions or emergent categories (Morgan, 1988). Relevant information was assigned as individual data units.

All data units were then sorted by category. These initial categories were expanded to include additional categories or themes that emerged from each of the focus group discussions. Once specific categories were identified, the relevant information and salient quotes from the transcripts were sorted by category using Ethnograph, a qualitative data analysis computer program.

Data from each focus group were examined separately, indexed by focus group, and compiled with data from all other groups. This allowed for comparisons of the themes that emerged both across and within groups.

Credibility Procedures. At the completion of each of the two phases of data analysis (i.e., 1st phase-identifying relevant data units; 2nd phase-categorizing data units), the two researchers met to compare notes. If there was disagreement between researchers regarding any data unit, it was discussed until consensus could be reached. This allowed for the final conclusions to be considered more "verifiable" in that another researcher could arrive at similar conclusions using the available documents and raw data (Krueger, 1988). In addition, the data trail procedures will allow for an outside expert to perform the necessary data audit once the final research is completed.

\section{RESULTS}

Although each of the focus groups was unique, all four groups shared common issues and similar experiences. The focus group data were collapsed into three broad categories that specifically related to family issues:

- Creation of a vision for the future.

- Family and student involvement in the transition planning process.

- Family involvement in facilitating self-determination.

Under each of these broad categories, several themes and subthemes emerged.

\section{Family Influence on the Creation of a Vision for the Future}

The focus group participants had definite dreams for their future. In fact, the majority of students saw their future as bright. Students were asked about their future job and career expectations, where they wanted to live, whether they planned to attend a postsecondary school, and about their plans for social relationships and marriage. The overarching vision was positive and could be described as "The American Dream"-or as one student encapsulated the sentiments of the majority of participants: "I want to go to college, get a job, and get married." Very few students viewed their future as negative, and when negative future expectations were expressed, they were not often shared by classmates. Probably the most remarkable aspect of the development of a vision for the future was the influence that families have had on their sons and daughters with disabilities, particularly in the areas of career aspirations and living on their own.

Careers. The students in the focus groups identified a wide array of careers and occupations 
as possibilities for their future. Some of the reasons for choosing their possible careers were practical ones such as money, or were based on school vocational experiences. The influence of families on career choices, however, was clearly evident by the overwhelming number of statements that students made about their families.

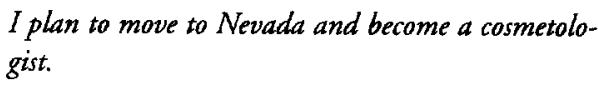

Why do you want to move to Nevada?

Because my aunt lives there and she's a cosmetologist.

For many of the students, the careers that they were considering were directly related to a family member with a similar career. The careers that students were interested in because of family connections included pediatrician, veterinarian, nurse, airline industry worker, restaurant worker, diesel mechanic, and cosmetologist. The family members that influenced these young adults included mothers, fathers, aunts, uncles, brothers, sisters, and cousins. What was surprising, however, was the informality with which the students had decided on possible careers. The majority of these students had not had any formal discussions with family members about their careers. They were interested in the career due to the informal role models that family members have played in their lives.

Living on Their Own. The first response to the question of "Where do you want to live after high school?" was to move to exotic places like Hawaii, France, Las Vegas, Liverpool, Africa, or just "a big city, a humongous city!" The second response was to move to a location where they would have family and social supports:

I'm gonna go to [the] Vo-Tech. I might not this year, not after senior year, but I'm going to wait a year and go with Janelle, she's another friend. . . . I'm going to live with my uncle.

In fact, the issue of family supports often influenced decisions about where a student might go for postsecondary education and training:

It's kind of a toss-up with a college I want to go to right now. I'm looking at Vo-Tech, I mean I could drive back and forth over there and live with my parents.... If I go to [the] Community [College].
... I've got grandparents that live up there. . . I've got nobody to live with down there [different town with a second community college], it's just like moving to a new country and trying to live on your own. It's going to be a little different than what I'm use to, and that's what is scaring me right now.

\section{Family Involvement in the Transition Planning Process}

Within the category of "family involvement in the transition planning process," several subcategories emerged: (a) starting the planning process, (b) Should families be involved in planning? (c) How have or should families be involved? (d) What barriers do families face in helping to plan for the future? and (e) involving student and family in IEP meetings.

Starting the Planning Process. The majority of students reported that they had not begun an identified or formal process of planning for their future. For many of the students, this was because they felt they were too young to be worrying about such matters, despite what some of their older classmates might tell them:

Can you think of any advice you would give us about how you would better prepare kids for the future?

Older student: I think I would start by, you know like I said, starting out in the 7th-grade year, talking to them about what kind of things they like to do, kind of work on those things. Sit down and talk to them individually about what kind of things they're planning on doing and just let them know that you guys are there and you guys are supportive.

Okay, now I want to ask you all who are 13 and 14. What do you think about what she says?

1st younger student: It's kind of like you guys are getting a little too old for us.

So you think they're too grown-up?

I st younger student: We still got a little while.

2nd younger student: You should wait until the 9th grade before worrying about getting a job or anything, because you can't get a job until you're at least 14 .

A few students reported that their families had started some discussions regarding life after high school: 
Have you had any meetings that have focused on planning for your future?

Well, not exactly, but my parents bave been giving me some ideas and stuff, and some teachers here have been giving me some ideas and I've been thinking, because my cousin, my one cousin is in it and so was $m y$ dad, he was in heavy equipment. My cousin was a diesel mechanic, and I was thinking of going out for those two because I heard that you make a lot of money and it would really be good for me.

Overall, the students with disabilities who participated in the four focus groups did not appear to be actively involved in any systematic transition planning. The few exceptions were a few students who were in their senior year of high school and who had had been involved in a transition planning process facilitated by their school district. Among those students who indicated at least a minimal level of thinking about their future, it was evident that their families were involved in this in an informal way.

What is interesting to note is the lack of direct comments pertaining to the role of families as a deliberate catalyst for starting the planning process. The students did not mention their families urging or encouraging them to begin to think about the furure. In a few cases where there was a clear and definite change approaching (e.g., their senior year, getting married, moving out of the house), then students talked about the role that their families have played in helping them to plan for these future changes. But again, the comments from these students indicated that the process was informal:

How about your family? Have they been involved?

Well, my mom . . kind of because I told her once I turn 18 that I was thinking about moving out and she told me that once you move out, once you turn 18 and move out of your parents' house, you're dropped off the insurance and stuff so you have to get your own insurance. Can't go crawling back to mommy and daddy.

Should Families Be Involved in Planning for the Future? Students indicated that a variety of people were involved in helping them to plan for their future, including boyfriends, parents, siblings, extended family members, teachers, adult service providers, classmates and friends, and other community members (e.g., employers). The majority of students, however, indicated that their families were the primary source of future planning and that this planning was informal at best:

We really don't talk about like, we're talking about my future, you know... if I come home and have a bad day or something like that, shell just kind of give me a pep talk, you know. ... It's not really future, but she just like, she just gives me pep talks or something like that, pretty much she supports me.

Most students stated that they felt that their family should be involved in helping them plan for their future:

My mom wants us not to be like her, so she'll go do what she has to so we can get a good education and go to college and stuff like that. And she said shell kick our butt if we drop out of school.

The majority of students identified their families as being involved. However, several students indicated the opposite. For these students, their families were not involved in their lives (students were in foster homes), or the students felt that they should assume full responsibility for planning for their own future.

How Have or Should Families Be Involved? Students identified a wide range of ways that family members have been involved or should be involved in helping them to plan for their future. The ways that families can and should be involved in planning ranged across all aspects of their current and furure lives including (a) making sure that they stay in high school, (b) planning for and helping to pay for college, (c) helping them move out on their own, and (d) helping them find a job. The students identified a wide range of family members who should be or have been involved in various aspects of their lives. These included both immediate and extended family members. The students discussed both concrete ways that families should be involved, such as paying for college, as well as more informal methods, such as just spending time talking with them or helping them with their homework.

What Barriers Do Families Face in Helping Plan for the Future? Several issues were evident when the discussion turned to barriers to family 
involvement in transition planning. Probably the most pressing issue that students identified as a barrier to having their families involved was the conflicts and disagreements between the student and his or her family:

How about when you disagree? Do you and your parents or family always agree on what you think is best?

No. $[M y]$ parents think they're right and you think you're right so you get in a fight and then you always win anyway because you'll walk outside the house and do it anyway.

Tied into this issue were the frustrations the students felt because they didn't think that their families gave them enough responsibilities. Another issue that was raised in two of the focus groups was the concern that families were not thinking about their futures, because they did not see the immediacy of the impending future:

Why do you think it's hard for your family to think about you guys being on your own?

Because you've lived with them all your life and they're used to you being there all the time.

Student and Family Involvement in IEP Meetings. Students were asked about their involvement in IEP meetings since the Individuals with Disabilities Education Act (IDEA) authorizes student and family involvement before a student begins the transition process and mandates it after the student is 16 or earlier, as appropriate, when transition planning is initiated as part of the IEP. The majority of students knew about their IEP meetings, and they indicated that at least one member of their family (usually their mother) attended these meetings. It was also clear, however, that several students did not know precisely what an IEP was, and of those students who knew what their IEP meeting was, few had actually attended their meetings. There were a variety of reasons for this lack of attendance, starting with the fact that they had never been invited to a meeting. One student stated that his mother and father would not allow him to attend meetings. When asked why they would not allow him to go, he stated:

I talked to my dad about my meetings but he told me [he] don't care about them anymore.
He's not interested? Does he still go?

He goes but he don't care.

Does your mom go?

She don't care either. I don't know what the deal is but my mom and dad don't like going to the meetings. . they think they're so stupid.

The majority of those who had not been to their meeting, however, had been invited and had decided not to attend. The primary reasons for deciding not to attend was that IEP meetings were meaningless and not relevant to planning for their future. Other students described their negative experiences at meetings as the reason for not wanting to attend.

It should be noted that not all of the students perceived their IEP meetings as negative. However, it was clear that those students who went to their meetings and who reported that they were active participants in their meetings were the only ones who saw any value in the IEP process. This was a small minority among all of the focus group participants. Overall, none of the students related incidents that indicated that their families had discussed IEP goals with them prior to the meeting or that they went into meetings with a sense of agreement on certain issues. The students did not describe any examples of their families supporting them or advocating for them during difficult meetings.

\section{Family Involvement in Facilitating Self-Determination.}

Students were asked a series of questions pertaining to self-determination and the opportunities they have had to make decisions in their lives. It was evident that families either facilitated:

\footnotetext{
When I was 13 my parents said that I need to start learning my own responsibilities and my parents would say you know, at this age I can start learning what's abead in the future, so they let me have my own responsibilities.
}

or hindered self-determination:

My mom and dad are very strict. I don't get to go to any parties. I want to control my own life.

While some students appeared to have more opportunities in making day-to-day deci- 
sions, most students were able to identify some areas where their parents made the decisions. These ranged from simple issues, such as having to do household chores, to more critical areas of their lives:

\section{I have some control of my life. I mean, like I have control whether or not I come home on time or not and whether or not I walk out of the house when I get grounded, especially whether or not I walk out of the bouse in front of my parents or not. But you know my parents have a choice of whether or not I get put in [out of home] placement.}

For some students, there was a real sense that they were responsible enough to make important decisions about their own lives. These decisions ranged along a continuum of risk such as deciding what activities they were involved in after school, to going to parties and staying out late, to drinking and doing drugs, to moving away from home. Many students who were able to make important decisions reported that they felt they possessed a level of responsibility that would be needed for adult life:

So how does that make you feel when you get to make decisions?

It makes me feel like I can do whatever I want right now. As long as I know that then I can correct my own mistakes. I mean if we get to make our decisions-if our parents are not making our decisions now, then we're getting pretty you know what it should be like in adult life.

It appeared that the students who felt they had opportunities to make decisions usually were able to communicate with their parents and felt that their parents were supportive of their decisions:

[If] my parents don't like it and we usually bave a seat in their living room and well talk it out and discuss it, and then well come up with another solution and do it a different way.

In other situations, students reported parental consequences when they made poor decisions. Many of the students discussed the fact that they respected and appreciated their parents' involvement in supporting them to make decisions:

I wanted to say parents [it seems as if we] don't like our parents, but really if you think about it, you know, they aren't that bad because they give you your own responsibility.

It is interesting to note that students overwhelmingly reported that the "big decisions" that they were making included: staying out late (past their curfew), drinking and driving, doing drugs, having sexual experiences, and moving away from home. However, students did not discuss any particular strategies that their families used to facilitate their self-determination. Clearly, this is an area that needs further exploration, particularly in light of the fact that these same students did not report any formal school curriculum or activities that were teaching these critical decision-making skills, and in some cases, the students realized how important these skills were.

\section{DISCUSSION}

A word of caution is in order related to the purpose and nature of qualitative research methodology. Using qualitative methods, the researcher inductively derives an understanding by attending to the participants' discussion rather than by testing or confirming hypothesis or theory (Krueger, 1988). The purpose of this focus group research, then, is not to broadly generalize the results to all students with disabilities, but to explore students' views concerning family involvement-perspectives that have been previously ignored. The issues that will be discussed in this section include: (a) family roles in creating a future vision; (b) family involvement in the planning process; and (c) family involvement in facilitating self-determination.

\section{Family Roles in Creating a Future Vision}

The students specifically described ways that families have helped them to develop a future vision related to career and lifestyle options. The finding that families influence career aspirations is not new (Super, 1990; Szymanski, 1994); however, it is the predominant means by which these students have begun to develop a career vision. The literature that does exist on family career influence, however, tends to focus on parental roles and does not include the contribution of extended family members. The comments from students in this study concerning the roles of grandparents, aunts, uncles, cousins, and siblings 
is extremely noteworthy, and data suggest that extended family might be considered as powerful partners in career preparation.

Equally striking is that relatively few students identified their school-based vocational training experiences as impacting career decisions. In some instances, a lack of a systematic and effective community-based vocational program was the cause; but in other cases, students' vocational experiences just were not as relevant to them as were their families'. Perhaps schools need to pay closer attention to the importance of including family careers as an aspect of a school vocational curriculum. The findings from these focus groups seem to indicate that emphasizing family careers is one area that might motivate students into developing career goals for the future.

The second component of developing a future vision focused on the students' having a concept of what supports might be needed for them to live on their own. Students expressed a preference to live close to their families so that they would have ongoing support. This is consistent with career literature that describes life-space considerations for transition (Super, 1990; Szymanski, 1994). Life-space issues refer to the different life roles (e.g., worker, community citizen, child, spouse, parent) and the ecological context within which those roles are carried out. These students clearly preferred ongoing contact with both the nuclear and extended family. This point raises the issue of how different family members could be involved in transition planning in terms of the supports that they can offer. It is noteworthy that very few students mentioned accessing professional support from the adult service system to assist them in their daily living needs.

Concerning career and lifestyle visions, parents and extended family members helped students shape their aspirations in an informal, almost implicit, manner with "families as role models." Based on the life-span perspective of transition (Hershenson, 1984; Szymanski, Hershenson, \& Power, 1988), early childhood years provide a strong foundation for career development (and likely for lifestyle development as well). Because family roles appear to be highly implicit in providing a vision for the future, whether it would be advantageous or detrimental to encourage this contribution to be more explicit is a useful question. If family roles are made more explicit in terms of developing a vision for the future, one must consider the potential positive and negative impacts of early, structured future planning during childhood years.

\section{Family Involvement in the Planning Process}

A critical theme that emerged across all focus groups was lack of systematic attention to the process of planning for the future. It was clear from the students' responses that the majority of students (with the exception of those who were seniors and facing the inevitable) have had only a loose connection with future planning. Interestingly, several younger students did not think it necessary to begin the planning process before 9th grade, whereas other older students felt planning should begin as early as 7 th grade.

Perhaps it is imperative to heed the warning from one young man, who stated: "If you start them so early, you're more or less training them to be adults." From this perspective, perhaps we need to consider what type of future planning is most appealing and relevant to students with disabilities and their families across the life-span. If schools start too soon and encourage families to do the same in a way that is not meaningful to the students and families, we may in the end lose students and families to the process because of our zeal to provide "early transition planning" training. It would be critical to avoid the pressures described by many parents in early intervention programs to constantly be "working" with their child to make developmental gains (Turnbull, Turnbull, \& Blue-Banning, 1994).

The majority of students identified certain family members as being able to provide support during the transition process. It might be a grandparent they were going to live with, or their father who has helped them find a job. The students frequently mentioned the ongoing connections with family members after graduation from high school. This raises the issue of the importance of the family in the "long haul." Families and professionals must develop a more extensive understanding of the roles that families play throughout adulthood for people with disabilities. Perhaps a critical element of transition planning is the identification of both immediate and extended family 
who will be involved in supporting the young adult after graduation from high school.

Of great concern is the finding that the majority of students reported the IEP process as irrelevant. The lack of student attendance at meetings is just the tip of the iceberg. More striking is the overall picture in which students are not actively engaged or involved in making decisions regarding their goals and objectives, including those involving life after high school. Disappointedly absent from the student descriptions of IEP meetings was any reference to a sense of family "solidarity" in participation. By family solidarity, we mean the partnership of students, parents, and extended family working in advance to formulate priority issues and attending the conference with a sense of unanimity in sharing their visions, goals, strengths, and needs for immediate and ongoing support.

Given the data shared from the students in the focus group concerning the potent role of parents and extended families in developing future visions related to career and lifestyle options, as well as in their preferences for receiving ongoing family support, it would appear that a major need for IEP model development would be preparation of family members to collaborate with their students. The most exciting work in this regard is from the person-centered planning literature regarding models such as the McGill Action Planning System (Forest \& Pierpoint, 1992), Personal Futures Planning (Mount \& Zwernik, 1988), Essential Lifestyle Planning (Smull \& Harrison, 1992), and Group Action Planning (Turnbull, Turnbull, \& Blue-Banning, 1994). All of these person-centered planning approaches place strong emphasis on creating connections among the person with a disability, nuclear and extended family, professionals, friends, and community citizens. Almost all person-centered planning has occurred outside of the formal IEP process, likely because of concern that the general atmosphere of IEP meetings would stifle the essence of person-centered planning. An issue for future research is why these processes seem to have benefits that the IEP transition planning process lacks.

\section{Family Influence on Self-Determination}

Wehmeyer (1992b) suggested that being self-determined, a primary causal agent in one's life, means that students act autonomously. Although there is a growing literature on self-determination (Sands \& Wehmeyer, in press), researchers have not provided sufficient explication of the interaction between self-determination and a family systems orientation to ongoing family support. It was clear that a number of students from the focus groups are seeking autonomy in making certain kinds of decisions, but they are also seeking ongoing family support. Interestingly, no students indicated support for or training in self-determination for themselves or their families had been part of the transition preparation process. They also did not mention any explicit strategies that their families had used in addressing issues of evolving autonomy over the lifespan.

It is critically important for special education leaders from across the age span to collaborate in the development of family-student-school partnership models. From the earliest ages, these models need to incorporate a much stronger emphasis on self-determination in enhancing students' autonomy, even during early childhood years, to express their preferences for activities and to assess their strengths and needs. In particular, family roles need to be conceptualized to ensure that parents and extended family have opportunities to be collaborators with their son or daughter in collective decision making. Thus, appropriate roles need to be delineated for students and families to experience self-determination at younger ages and for families to be involved in supporting their son or daughter's autonomy in planning meetings at older stages.

\section{CONCLUSION}

The findings reported here are the first phase of an ongoing research project designed to solicit the viewpoints and perceptions of secondary students with disabilities regarding their experiences with transition planning. Given the nature of qualitative research methodology, we emphasize that the purpose of this research is not to generalize broadly the results that we have obtained to all students with disabilities, but to give voice to students' perspectives concerning family involvement that has typically not been part of the professional literature. The findings of this research, therefore, 
can be used to generate additional research directions and demonstration models regarding the involvement of students with disabilities and families in the transition planning process.

\section{REFERENCES}

Everson, J., \& Moon, S. (1987). Transition services for young adults with severe disabilities: Defining professional and parental roles and responsibilities. Journal of the Association for Persons with Severe Handicaps, 12(2), 87-95.

Forest, M., \& Pierpoint, J. C. (1992, October). Putting kids on the MAP. Educational Leadership, 26-31.

Gardner, J. F., Chapman, M. S., Donaldson, G., \& Jacobson, R. (1988). Toward supported employment: $A$ process guide for planned change. Baltimore: Paul $\mathrm{H}$. Brookes.

Goldberg, S. S., \& Kuriloff, P. J. (1991). Evaluating the fairness of special education hearings. Exceptional Children, 57, 546-555.

Hershenson, D. B. (1984). Vocational counseling with learning disabled adults. Journal of Rehabilitation, 50 , 40-44.

Johnson, L. J., \& LaMontagne, M. J. (1993). Research methods: Using content analysis to examine the verbal or written communication of stakeholders within early intervention. Journal of Early Intervention, 17(1), 7379.

Kerwin, C., Ponterotto, J. G., Jackson, B. L., \& Harris, A. (1993). Racial identity in biracial children: A qualitative investigation. Journal of Counseling Psychology, $40(2), 221-231$.

Krueger, R. A. (1988). Focus groups: A practical guide for applied research. London: Sage.

Lincoln, Y. S., \& Guba, E. G. (1985). Naturalistic inquiry. London: Sage.

Martin, J. E., Marshall, L. H., \& Maxson, L. L. (1993). Transition policy: Infusing self-determination and self-advocacy into transition programs. Career $D e$ velopment for Exceptional Individuals, 16(1), 53-61.

McNair, J., \& Rusch, F. R. (1991). Parent involvement in transition programs. Mental Retardation, 29(2), $93-$ 101.

Mithaug, D. E., Martin, J. E., \& Agran, M. (1987). Adaptability instruction: The goal of transitional programming. Exceptional Children, 53, 500-505.

Morgan, D. L. (1988). Focus groups as qualitative research. Qualitative Research Methods Series, 16. London: Sage.
Morgan, D. L., \& Krueger, R. A. (1993). When to use focus groups and why. In D. L. Morgan (Ed.), Successful focus groups: Advancing the state of the art (pp. 3-19). Newbury Park: Sage Publication.

Morningstar, M. E., Sarkesian, S., \& Tisdale, C. (1993, July). Report of the transition training needs in Kansas. Lawrence: University of Kansas, Department of Special Education.

Mount B., \& Zwernik, K. (1988). It's never too early, it's never too late: $A$ booklet about personal planning for persons with developmental disabilities, their families and friends, case managers, service providers, and advocates. St. Paul, MN: Metropolitan Council. (ERIC Document Reproduction Service No. ED 327 997)

Sales, P., Metzler, H. M., Everson, J. M., \& Moon, M. S. (1991, October). Quality indicators of successful vocational transition programs. Journal of Vocational Rehabilitation, 1(4), 47-63.

Sands, D., \& Wehmeyer, M. (Eds.). (in press). Self-determination across the lifespan: Theory and practice. Baltimore: Paul H. Brookes.

Schultz, R. P. (1986). Establishing a parent-professional partnership to facilitate competitive employment. In $\mathrm{F}$. R. Rusch (Ed.), Competitive employment issues and strategies (pp 289-302). Baltimore: Paul H. Brookes.

Smull, M., \& Harrison, S. B. (1992). Supporting people with severe reputations in the community. Alexandria, VA: National Association of State Mental Retardation Program Directors.

Stewart, D. W., \& Shamdasani, P. N. (1990). Focus groups: Theory and practice. Applied Social Research Methods Series, 20. London: Sage.

Super, D. E. (1990). A life-span, life-space approach to career development. In D. Brown, L. Brooks, \& Associates (Eds.), Career choice and development: Applying contemporary theories to practice (2nd ed., pp. 197-261). San Francisco: Jossey-Bass.

Szymanski, E. (1994). Transition: Life-span and lifespace considerations for empowerment. Exceptional Children, 60, 402-410.

Szymanski, E. M., Hershenson, D. B., \& Power, P. W. (1988). Enabling the family in supporting transition from school to work. In P. W. Power, A. Dell Orto, \& M. B. Gibbons (Eds.), Family interventions throughout chronic illness and disability (pp. 216-233). New York: Springer.

Thornin, E. J., \& Irvin, L. K. (1992). Family stress associated with transition to adulthood of young people with severe disabilities. Journal of the Association for Persons with Severe Handicaps, 16(1), 31-39. 
Todis, B., \& Singer, G. (1991). Stress and stress management in families with adopted children who have disabilities. Journal of the Association for Persons with $S e$ vere Handicaps, 19(1), 3-13.

Turnbull, A. P., \& Turnbull, H. R. (1990). Families, professionals and exceptionality: A special partnership (2nd ed). Columbus, $\mathrm{OH}$ : Merrill.

Turnbull, A. P., Turnbull, H. R., \& Blue-Banning, M. J. (1994). Enhancing inclusion of infants and toddlers with disabilities and their families: A theoretical and programmatic analysis. Infants and Young Children, $7(2), 1-14$.

Van Reusen, A. K., \& Bos, C. S. (1990). IPLAN: Helping students communicate in planning conferences. TEACHING Exceptional Children, 22(4), 30-32.

Van Reusen, A., \& Bos, C. (1994). Facilitating student participation in individualized education programs through motivation strategy instruction. Exceptional Children, 60, 466-475.

Wehmeyer, M. L. (1992a). Self-determination and the education of students with mental retardation. Education and Training in Mental Retardation, 27(4), 302314.

Wehmeyer, M. L. (1992b). Self-determination: Critical skills for outcome-oriented transition services. The Journal for Vocational Special Needs Education, 15, 3-7.

\section{ABOUT THE AUTHORS}

MARY E. MORNINGSTAR (CEC KS Federation), Project Director; ANN P. TURNBULl(CEC \#665), Co-Director; and H. RUTHERFORD TURngull II (CEC \#665), Co-Director, Beach Center on Families and Disability, University of Kansas, Lawrence.

For questions concerning this article, please contact Mary E. Morningstar, Beach Center on Families and Disability, University of Kansas, 3111 Haworth Hall, Lawrence, KS 66006. (e-mail address: mmorningstar@quest.sped.ukans.edu).

\section{PROFESSIONAL OPPORTUNITIES}

(Continued from page 286.)

ASSISTANT PROFESSOR IN SPECIAL EDUCation: The Department of Educational Psychology of the Graduate School of Education at Rutgers University invites applications for an anticipated tenure-track position in Special Education at the Assistant Professor level, commencing September 1, 1996. Requirements include: (1) expertise in assessment and remediation of learning and behavior problems in students with mild or moderate disabilities in grades K-12; (2) experience in preparing teachers and learning consultants for work in inclusive settings as well as special classes; (3) a developed program of research in special education with evidence of scholarly productivity; and (4) a strong commitment to quality teaching at both undergraduate and graduate levels. Teaching experience in public schools and grant writing skills will enhance the application. Responsibilities include: (1) teaching at both undergraduate and graduate levels; (2) developing and maintaining an active research program; (3) supervision of student research; (4) solicitation of extramural grant funding; and (5) service activiries. Salary and benefits are highly competitive. Candidates should send a letter of application including statements of research and teaching interests, vita, and the names, positions, and phone numbers of three people who can provide references to: GSE Search Committee, Graduate School of Education, Rutgers, The State University of New Jersey, 10 Seminary Place, New Brunswick, NJ 08903-5050. Applications must be received by December 20, 1995. Rutgers University is an Equal Opportunity/Affirmative Action employer. We are particularly intersted in receiving applications from members of underrepresented groups. For more information contact Dr. Richard DeLisi at 908/932-7496 ext.318 or DELISI@rci.rutgers.edu. 